\title{
MENINGKATKAN HASIL BELAJAR SERVIS ATAS BOLA VOLI MENGGUNAKAN MEDIA MODIFIKASI PADA SISWA KELAS VII SMP NEGERI 8 LANGSA TAHUN AJARAN 2019/2020
}

\author{
Zulfikri \\ Universitas Sains Cut Nyak Dhien Langsa \\ Zoelbarca@Gmail.com
}

\begin{abstract}
ABSTRAK
Secara umum penelitian ini bertujuan untuk meningkatkan hasil belajar servis atas bola voli pada siswa kelas VII SMP Negeri 8 Langsa Tahun Ajaran 2019/2020. Dimana penelitian ini penerapannya menggunakan penelitian tindakan (Action Research). Subyek penelitian ini adalah siswa kelas VII SMP Negeri 8 Langsa. Dari tes hasil belajar siklus I diperoleh sebanyak 24 orang siswa dengan nilai setelah dikonversikan sebesar $(70,58 \%)$ telah mencapai tingkat ketuntasan belajar sedangkan 10 orang siswa $(29,42 \%)$ belum mencapai tingkat ketuntasan belajar. Dengan nilai rata-rata hasil belajar setelah dikonversikan adalah 72,54 (2) dari tes hasil belajar siklus II diperoleh data sebanyak 30 orang siswa dengan nilai setelah dikonversikan sebesar $(88,23 \%)$ yang telah mencapai ketuntasan dalam belajar dan 4 orang siswa $(11,77 \%)$ masih belum tuntas. Dengan nilai rata-rata hasil belajar setelah dikonversikan 78,67.
\end{abstract}

Kata Kunci : Modifikasi pembelajaran, hasil belajar, servis atas bola voli

\section{IMPROVE SERVICE LEARNING OUTCOMES VOLLEY BALL USING MODIFICATION MEDIA IN CLASS VII STUDENTS OF STATE 8TH MIDDLE STATE ACADEMIC YEAR 2019/2020}

\begin{abstract}
In general, this research aims to improve the learning outcomes of volleyball service in class VII students of SMP Negeri 8 Langsa in the Academic Year 2019/2020. Where this research is applied using action research. The research subjects are Grade VII students of SMP Negeri 8 Langsa. From the first cycle of learning outcomes tests obtained as many as 24 students with scores after being confirmed (70.58\%) have reached the level of mastery learning while 10 students $(29.42 \%)$ have not reached the level of mastery learning. With an average value of learning outcomes after being confirmed is 72.54 (2) from the second cycle of learning outcomes tests obtained data of 30 students with grades after being confirmed $(88.23 \%)$ who have achieved mastery in learning and 4 students (11.77\%) still incomplete. With the average value of learning outcomes after being confirmed 78.67 .
\end{abstract}

Keywords: modification of learning. learning outcomes, service over volleyball

Dipublikasikan Oleh :

UPT Publikasi dan Pengelolaan Jurnal

Universitas Islam Kalimantan Muhammad Arsyad Al Banjari Banjarmasin 


\section{PENDAHULUAN}

Kualitas kehidupan bangsa ditentukan oleh faktor pendidikan. Pendididikan memegang peranan penting untuk menciptakan kehidupan yang cerdas, damai, terbuka dan demokrasi. Oleh karena itu pendidikan hendaknya dikelola baik secara kualitas maupun kuantitas. Untuk mewujudkan hal tersebut, perlu memperhatikan banyak hal salah satu nya yaitu keadaan tenaga pendidik dan usaha peningkatan mutu pendidikan.

Pendidikan jasmani sebagai bagian integral dari sistem pendidikan nasional juga dibutuhkan oleh masyarakat. Eksistensi pendidikan jasmani dalam lingkup pendidikan nasional dapat dilihat dari definisi pendidikan jasmani. Cabang olahraga voli merupakan salah satu cabang olahraga yang banyak penggemarnya di seluruh dunia, hal ini terbukti dengan semakin banyaknya berdiri klub bola voli di perkotaan maupun di pedesaan.

Begitu juga di Sekolah SMP Negeri 8 Langsa dimana saat pelaksanaan kegiatan belajar mengajar mengenai materi bola voli, masih banyak siswa yang belum memenuhi syarat kelulusan. jika dilihat berdasarkan hasil observasi terhadap siswa Kelas VII SMP NEGERI 8 LANGSA bahwa berdasarkan Kriteria Ketuntasan Minimal (KKM) yaitu 70 menunjukan bahwa masih banyak siswa yang tidak tuntas. Jika dianalisis, hal tersebut terjadi dikarenakan kesalahan siswa pada saat melakukan servis atas. banyak hal-hal penting yang tidak dilakukan oleh siswa sehingga untuk tercapainya tujuan pembelajaran akan sangat sulit.

Salah satu nya pada saat impact bola dengan telapak tangan. masih banyak siswa yang kurang memahami cara melakukan hal tersebut, sehingga proses impact hanya sekedar menyentuh bola saja tanpa memahami teknik tersebut. Hal ini sering dilihat pada saat siswa melakukan servis atas, dan bola nya tidak melewati net.

Kemudian dari sarana dan prasarana di SMA NEGERI 8 LANGSA Kota Madya Langsa yang masih minim. Hal ini dapat dilihat dari jumlah bola voli yang dimiliki sekolah tersebut hanya berjumlah 2 buah. Sehingga kegiatan belajar mengajar tidak efisien.

Berdasarkan dari latar belakang tersebut, peneliti akan mengadakan penelitian mengenai "Upaya Meningkatkan Hasil Belajar Servis Atas Bola Volli Dengan Menggunakan Media Modifikasi Pada Siswa Kelas VII SMP NEGERI 8 LANGSA Kota Madya Langsa Tahun Ajaran 2019/2020.”

\section{METODE PENELITIAN}

Penelitian ini dilaksanakan di SMP Negeri 8 Langsa. Waktu pelaksanaan penelitian pada awal bulan Mei sampai Juni 2020. Dengan frekuensi penelitian adalah satu kali pertemuan dalam satu minggu sesuai dengan RPP dan bulan pertama sebagai pelaksanaan penelitian di lapangan dilanjutkan dengan pengolahan data dan analisis data pada bulan berikutnya. Subyek penelitian dalam penelitian peningkatan pembelajaran pendidikan jasmani Bola Voli melalui Modifikasi Media Pembelajaran adalah siswa kelas VII yang berjumlah 34 orang yang ada di SMP Negeri 8 Langsa.

Analisis data dalam peniliaian ini adalah deskriptif kualitatif dan kuantitatif. data kualitatif membandingkan data tes awal dan hasil tes setelah siklus 1 dan 2 . Sedangakan kuantitatif adalah refleksi dalam setiap siklusnya berdasarkan hasil observasi yang terekam dalam catatan lapangan, dokumentasi, dan observasi. Analisis data dilakukan secara deskriptif dengan membandingkan hasil pencapaian dengan indikator keberhasilan.

\section{HASIL DAN PEMBAHASAN \\ Siklus 1}

Observasi dan pengamatan dilakukan oleh peneliti beserta guru pendidikan jasmani mulai dari awal pelaksanaan tindakan sampai akhir pelaksanaan tindakan pembelajaran kepada siswa siswi SMP Negeri 8 Langsa melalui penerapan media modifikasi sebagai upaya meningkatkan hasil belajar siswa pada materi servis atas bola voli. Dari hasil observasi dapat dilihat bahwa kegiatan pembelajaran telah berlangsung dengan baik namun masih banyak beberapa kekurangan dalam proses pembelajaran.

Guru pendidikan jasmani dan peneliti memberikan materi servis atas dengan menggunakan media modifikasi. Di dalam materi servis atas bola voli yang diberikan, guru dan peneliti menjelaskan

Dipublikasikan Oleh:

UPT Publikasi dan Pengelolaan Jurnal

Universitas Islam Kalimantan Muhammad Arsyad Al Banjari Banjarmasin 
tahapan-tahapan teknik melakukan servis atas bola voli. Dengan menggunakan media modifikasi siswa dapat lebih mengembangkan materi pelajaran sesuai dengan kemampuannya masing-masing. Pada proses pembelajaran berlangsung, peneliti melakukan pengamatan pada guru untuk mengetahui apakah proses pembelajaran yang dilaksanakan guru berjalan dengan baik.

Tabel 4.6. Hasil Post-Test I (Siklus I) Servis Bawah Bola Voli

\begin{tabular}{|l|l|c|c|l|}
\hline No & Hasil Tes & Jumlah Siswa & Persentase & Keterangan \\
\hline 1 & skor $>70$ & 24 & $70,58 \%$ & Tuntas \\
\hline 2 & skor $<69$ & 10 & $29,42 \%$ & Tidak Tuntas \\
\hline \multicolumn{2}{|c|}{ Jumlah Rata-rata } & 34 & $100 \%$ & \\
\hline \multicolumn{2}{|c|}{} & 72,54 & Tidak Tuntas \\
\hline
\end{tabular}

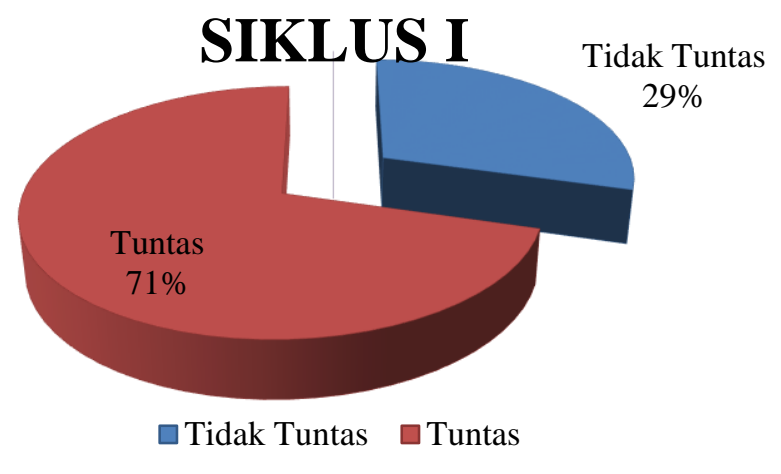

Gambar 4.10. Perbandingan Ketuntasan Belajar Pada Siklus I

Berdasarkan tabel dan grafik hasil post-test I diatas dapat dilihat bahwa hasil belajar siswa dalam proses pembelajaran servis bawah pada permainan bola voli ternyata telah terjadi peningkatan. Dari 34 siswa yang menjadi subjek dalam penelitian ini, ternyata telah terdapat 24 siswa $(70,58 \%)$ yang memiliki ketuntasan belajar servis bawah pada permainan bola voli, sedangkan 10 siswa $(29,42 \%)$ masih belum memiliki ketuntasan belajar servis bawah pada permainan bola voli. Nilai rata-rata yang diperoleh pada siklus I ini mencapai 72,54.

Dari hasil observasi yang dilakukan memperhatikan kemampuan awal siswa yang belum memenuhi ketuntasan belajar secara klasikal, terbukti dengan hasil tes pertama siswa yang belum mencapai ketuntasan belajar,dan diperlukan lagi untuk melakukan siklus ke II.

\section{Siklus II}

Dalam siklus II ini proses belajar mengajar berjalan dengan baik jika dibandingkan dengan siklus I. Jika pada siklus I aktivitas peserta didik secara keseluruhan yang memiliki ketuntasan belajar adalah 24 siswa $(70,58 \%)$ dan meningkat pada pada siklus II menjadi 30 siswa $(88,23 \%)$ yang telah mencapai ketuntasan hasil belajar servis atas pada permainan bola voli.

Pada akhir proses pembelajaran siklus II dilakukan post-test II untuk melihat hasil belajar servis bawah pada permainan bola voli yang diperoleh siswa kelas VII siswa siswi SMP Negeri 8 Langsa Tahun Ajaran 2019/2020.dapat dilihat tabel diskripsi dibawah ini :

Dipublikasikan Oleh :

UPT Publikasi dan Pengelolaan Jurnal

Universitas Islam Kalimantan Muhammad Arsyad Al Banjari Banjarmasin 
Tabel 4.7 Hasil Post-Test II (Siklus II) Servis Bawah Bola Voli

\begin{tabular}{|l|l|c|c|l|}
\hline No & Hasil Tes & Jumlah Siswa & Persentase & Keterangan \\
\hline 1 & skor $>70$ & 30 & $88,23 \%$ & Tuntas \\
\hline 2 & skor $<69$ & 4 & $11,77 \%$ & Tidak Tuntas \\
\hline \multicolumn{2}{|c|}{ Jumlah } & 34 & $100 \%$ & \\
\hline \multicolumn{2}{|c|}{ Rata-rata } & 78,67 & Tuntas \\
\hline
\end{tabular}

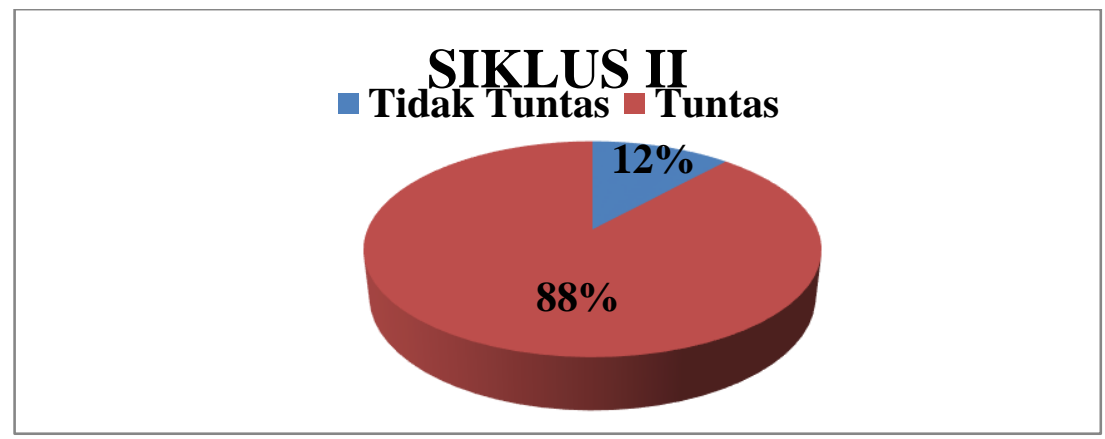

\section{Gambar 4.11 Diagram Ketuntasan Belajar Pada Siklus II}

Observasi II dilaksanakan untuk melihat apakah kondisi belajar mengajar sudah terlaksana sesuai program pengajaran ketika tindakan diberikan. Setelah test hasil belajar II diberikan kepada siswa maka diperoleh sejumlah informasi dari hasil test siswa tersebut yaitu servis bawah pada permainan bola voli.

Berdasarkan data hasil penelitian yang telah dipaparkan, secara umum dapat disimpulkan bahwa:

1. Masih ada 4 siswa $(11,77 \%)$ yang belum mencapai ketuntasan hasil belajar servis atas pada permainan bola voli yang belum mampu secara maksimal dalam pelaksanaan proses pembelajaran.

2. Sebagain besar siswa 30 siswa $(83,33 \%)$ yang telah mencapai ketuntasan hasil belajar servis atas pada permainan bola voli dan mampu menguasai teknik dasar belajar servis atas pada permainan bola voli dengan baik dan benar pada penilaian indikator 3, penilaian indikator 2 deskriptor no 2 dan 3 dan penilaian indikator 3 deskriptor no 1 dan 4 .

Berikut ini dapat dilihat nilai rata-rata hasil belajar servis atas pada permainan bola voli pada siswa kelas VII SMP Negeri 8 Langsa Tahun Ajaran 2019/2020 dari mulai tindakan test awal, proses pembelajaran siklus I, dan proses pembelajaran siklus II adalah sebagai berikut :

Tabel 4.8 Nilai Test Awal, Siklus I, dan Siklus II

\begin{tabular}{|l|l|l|c|l|}
\hline No & \multicolumn{1}{|c|}{ Hasil Tes } & \multicolumn{1}{|c|}{ Persentase } & Nilai Rata-Rata & \multicolumn{1}{|c|}{ Keterangan } \\
\hline 1 & Test awal & $\begin{array}{l}\text { Tuntas 52,94\% } \\
\text { Tidak Tuntas } 47,16 \%\end{array}$ & 68,12 & Tidak Tuntas \\
\hline 2 & Post-Test I & $\begin{array}{l}\text { Tuntas } 70,58 \% \\
\text { Tidak Tuntas } 29,42 \%\end{array}$ & 72,54 & Tidak Tunas \\
\hline 3 & Post-Test II & $\begin{array}{l}\text { Tuntas } 88,23 \% \\
\text { Tidak Tuntas } 11,77 \%\end{array}$ & 78,67 & Tuntas \\
\hline
\end{tabular}

Dipublikasikan Oleh :

UPT Publikasi dan Pengelolaan Jurnal

Universitas Islam Kalimantan Muhammad Arsyad Al Banjari Banjarmasin 


\section{Gambar 4.12 Diagram Test Awal, Post-tes I dan Post-test II}

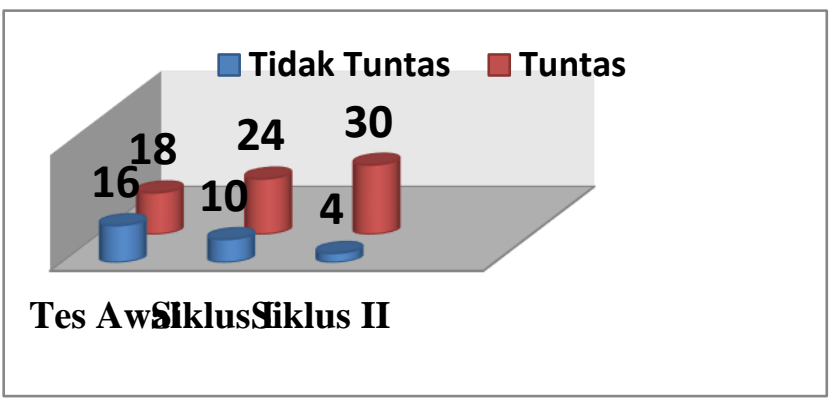

\section{PENUTUP}

Berdasarkan temuan dan kesimpulan dari hasil penelitian dapat dikemukakan beberapa implikasi sebagai berikut :

1. Pembelajaran pendidikan jasmani menggunakan penerapan modiufikasi pembelajaran memerlukan guru yang kreatif, baik dalam menyiapkan kegiatan pembelajaran maupun pengalaman belajar bagi anak, juga dalam memilih kompetensi dari berbagai mata pelajaran.

2. Penerapan modifikasi pembelajaran menggunakan alat yang sederhana dalam pembelajaran servis atas bola voli merupakan alternative dalam memecahkan beberapa masalah yang dihadapi guru dalam upaya mengaktifkan siswa dalam belajar.

3. Dalam setiap penerapan modifikasi media pembelajaran guru harus mampu menciptakan kelas yang konduksif agar hubungan interaktif siswa dengan guru, siswa dengan siswa dapat terwujud sehingga suasana kelas menjadi aktif dan menarik. Dalam hal ini guru harus mampu menjadi contoh dan teladan siswanya, tidak hanya dalam kata-kata tetapi juga dalam perbuatan sehari-hari.Dengan penerapan modifikasi media pembelajaran ini para siswa lebih tertantang, lebih aktif dan harus lebih serius.

Peneliti dapat memberikan saran-saran sebagi berikut :

1. Guru pendidikan jasmani harus kreatif dalam menyikapi kekurangan sarana dan prasarana pembelajaran yang ada di sekolahnya.

2. Guru hendaknya memiliki dan mendesain berbagai macam model-model pembelajaran, agar siswa tidak jenuh.

3. Penerapan teknologi dalam pendidikan jasmani juga diperlukan untuk meningkatkan kualitas proses pembelajaran.

4. Penyampaian pembelajaran hendaknya disesuaikan dengan keadaan siswa di masing-masing sekolah, supaya siswa dapat mengerti serta menguasai apa yang disampaikan oleh guru.

5. Guru dapat menerapkan metode pembelajaran pendidikan jasmani bola voli dengan memodifikasi media pembelajaran sebagai salah satu pendukung dalam mengajar, agar siswa takut, dan lebih aktif dalam proses pembelajaran. 


\section{REFERENSI}

Adang Suherman (2000). Dasar-Dasar Penjaskes. Departemen Pendidikan dan Kebudayaan Direktorat Jenderal Pendidikan Dasar dan Menengah Bagian Proyek Penataran Penataran Guru SLTP Setara D-III.

Agus Kristiyanto (2010). Penelitian TIndakan Kelas (PTK) Dalam Pendidikan Jasmani dan Kepelatihan Olahraga. Sebelas Maret University Press.

Arsyad, Azhar (2011). Media Pembelajaran. PT Raja Grafindo Persada, Jakarta.

Aunurrahman (2012). Belajar Dan Pembelajaran. Bandung: Alfabeta.

Bachtiar, Harsja W. (2008). Media Pendidikan. PT Raja Grafindo Persada, Jakarta.

Dimyati, Mudjiono (2006). Belajar Mengajar, Penerbit CV. Mustika Bandung.

Giri Verianti, Bangbang Samsudar (2009). Pendidikan Jasmani Olahraga dan Kesehatan. Untuk Siswa SMP-Mts Kelas VIII.

Hamalik Oemar (2010). Belajar Dan Kesulitan-Kesulitan Belajar. Bandung: Tarsito.

Suharsimi Arikunto (2010). Prosedur Penelitian. Penerbit PT Rineka Cipta.

Wahyu Pratama Bagus S. (2009).Pengaruh Latihan Dengan Modifikasi. Fakultas Ilmu Keolahragaan, Universitas Semarang. 